years. Curriculums in schools and for caterers should devote more attention to this and less to traditional cookery methods, which usually require a lot of fat. Catering contracts to hospitals and possibly educational institutions could include legal requirements to provide food which meets the target levels, on a par with current regulations on food hygiene.

The consumer also needs to know what is in packaged food. Food labelling should become mandatory and include ready made and possibly restaurant meals. Supermarkets can assist consumers by displaying low fat foods in prominent areas and by possibly introducing designated "healthy shopping" areas. More dietitians need to be trained and available to assist food manufacturers, retailers, the media, and caterers in changing eating habits, and sufficient dietitians must be available to talk directly to patients and the public. Reliance on the dissemination of advice by other health professionals is unsatisfactory because their training in nutrition has been neglected. In one survey, $90 \%$ of medical students and doctors thought that their present education in nutrition was inadequate. ${ }^{15}$

Lastly, the possibility of curbing or opposing the massive amount of advertising for unhealthy food and drink must be considered. Regular television screening within the home goes a long way to overturning the hard work of all those presently participating in health education.

\section{Future targets}

And what of the future? There are enormous gaps in our knowledge of exactly how much and how diet contributes to the cause and prevention of many other diseases, such as cancer. These gaps exist because nutrition research has been neglected since its heyday in the 1920 s and 1930 s. Only about $3 \%$ of the Medical Research Council's budget is currently allocated to nutrition related research. It is to be hoped that a political decision to invest in improved health through dietary measures will increase our knowledge of the effects of diet through adequate funding for medical aspects of nutrition.

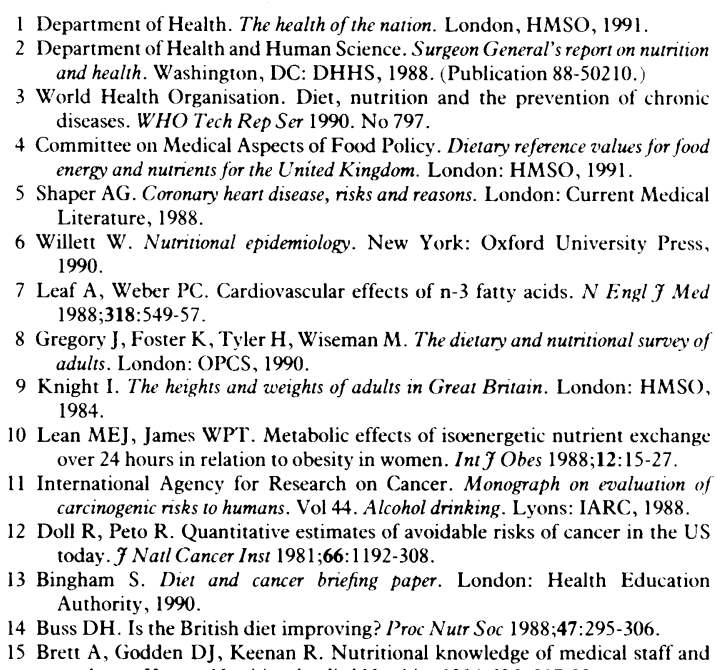

1 Department of Health. The health of the nation. London, HMSO, 1991.

2 Department of Health and Human Science. Surgeon General's report on nutrition and health. Washington, DC: DHHS, 1988. (Publication 88-50210.

3 World Health Organisation. Diet, nutrition and the prevention of chronic diseases. WHO Tech Rep Ser 1990. No 797.

4 Committee on Medical Aspects of Food Policy. Dietary reference values for food energy and nutrients for the United Kingdom. London: HMSO, 1991.

5 Shaper AG. Coronary heart disease, risks and reasons. London: Current Medical Literature, 1988.

6 Willett W. Nutritional epidemiology. New York: Oxford University Press, 1990.

7 Leaf A, Weber PC. Cardiovascular effects of n-3 fatty acids. N Engl . Y Med 1988;318:549-57.

8 Gregory J, Foster $\mathrm{K}$, Tyler $\mathrm{H}$, Wiseman $M$. The dietary and nutritional survey of adults. London: OPCS, 1990.

9 Knight I. The heights and weights of adults in Great Britain. London: HMSO, 1984

10 Lean MEJ, James WPT. Metabolic effects of isøenergetic nutrient exchange over 24 hours in relation to obesity in women. In $\mathcal{F}$ Obes 1988;12:15-27. 11 International Agency for Research on Cancer. Monograph on evaluation of carcinogenic risks to humans. Vol 44. Alcohol drinking. Lyons: IARC, 1988. 12 Doll R, Peto R. Quantitative estimates of avoidable risks of cancer in the US today. F Natl Cancer Inst 1981;66:1192-308.

13 Bingham S. Diet and cancer briefing paper. London: Health Education Authority, 1990.

14 Buss DH. Is the British diet improving? Proc Nutr Soc 1988;47:295-306.

15 Brett A, Godden DJ, Keenan R. Nutritional knowledge of medical staff and students. Human Nutrition Applied Nutrition 1986;40A:217-22.

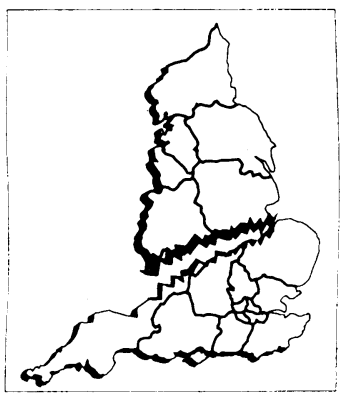

Rehabilitation Research

Unit, University of

Southampton, Level C,

West Wing, Southampton

General Hospital,

Southampton SO9 4XY

D L McLellan, FRCP,

Europe professor of

rehabilitation

BMF 1991;303:355-7

\section{Rehabilitation}

\section{L McLellan}

Rehabilitation is a very large subject for this small article. The case that it should be a key area in the government's strategy may be summarised as follows:

- People with disabilities are numerous and their needs great

- The benefits of appropriate intervention are an improvement in the duration and quality of life

- Intervention also improves the contribution that people with disabilities can make to their community and reduces the needs of informal carers

- The government's criteria in The Health of the Nation' specifically justify including rehabilitation (box).

The recent surveys by the Office of Population Censuses and Surveys have shown that disability is common and has a profound effect on disposable income, employment, and quality of life. ${ }^{4}$ The most common disabling conditions affect the musculoskeletal system and the special senses, but the greatest dependency results from neurological disorders, especially those that cause impaired cognitive function and behaviour in addition to physical disability. Although $10 \%$ of the general population have a disability of some kind, rehabilitation medicine services concentrate mainly on people with severe disabilities. These people include the 1000 or so in each health district between the ages of 16 and 65 who are unable to live at home for 24 hours or more without the physical help of another person-a group I shall subsequently refer to as people with appreciable dependency. ${ }^{5}$ This group probably has the greatest risk of avoidable complications and deterioration such as deformities, accidental injury, intercurrent infection, pressure sores, and poor levels of physical fitness. They are also prone to excess psychological stress, as are their informal carers and families. At the other end of the scale are people who have a considerable health related handicap despite successful medical or surgical treatment, the most notable example being people with epilepsy, whose difficulty in obtaining employment is out of all proportion to the disability experienced."

Some of the interventions of rehabilitation medicine are self evidently effective, such as training wheelchair users in the prevention of pressure sores and the skilled use of communication aids for people who cannot talk. Despite the lack of resources allocated to research in rehabilitation there is increasing evidence of effectiveness in its whole range from the outcomes of coordinated programmes for people with spinal cord injuries? and the effects of neglect on disabled teenagers ${ }^{8}$ to the impact of specific measures to improve communication and develop cognitive strategies that circumvent the effects of cognitive impairment. ${ }^{910}$

\section{The case against rehabilitation being a key area}

Neglect sets a precedent. Most medical graduates are profoundly ignorant of rehabilitation medicine and will readily identify priorities in other medical disciplines. Little research is funded by the government or by major charities in rehabilitation despite the difficulties of conducting research in this subject. It would be nice to think that this is because the problems of rehabilitation medicine have all been sorted out - but regrettably, it is simply evidence of marginalisation and neglect. 


\section{Government criteria including rehabilitation as a key area}

- A major theme of the document is to find the right balance between "the three key areas: prevention, treatment and rehabilitation"

- Avoidable disability, illness, and premature death are themselves key targets

- Because rehabilitation is served by health related activities in many government departments it tends to be marginalised. The challenge of identifying objectives with solutions that require collaboration between departments is specifically accepted

- Objectives and targets can be set which will enable progress to be made

- Rehabilitation is specifically identified as an area with clear scope for improvement. ${ }^{2}$ This is not only a matter of more resources but also of better targeting towards needs that are seen as important by the disabled person

- "Above all there is the need to maintain the quality of care and support for chronically sick people ... and handicapped people... in the face of some significant demographic changes."

- "There is a need for specific initiatives to address the health needs of particularly vulnerable groups ... who need specific targeted help."

- Specific interventions that offer significant improvement in outcome are readily available

\section{What should the targets be?}

The first thing to be said is that many people with disabilities have their own targets. ${ }^{11}$ Those that the Department of Health adopts should result from a process of discussion and negotiation in which people with disabilities are fully involved. I suggest that they should establish that the potential for personal rehabilitation has been realised, that an optimal level of function is maintained, and that the need for support of informal carers has been minimised.

To establish that the potential for personal rehabilitation has been realised, unrealised potential must be identified. Despite the impressive advances in techniques for doing this-for example, the Edinburgh rehabilitation index ${ }^{12}$ - doubt will always exist in relation to individual people. Outcome measures therefore need to apply either to averaged values derived from the relevant population or to percentages of people within the population who reach the required outcome targets.

Locomotion and mobility, the capacity for self care, communication, and employment are key factors in target setting because of the impact they have on the quality of life and the demands they make on services. ${ }^{3}$ For those incapable of open paid employment we need an indicator of whether their time is occupied in fulfilling activities. For carers outcome should particularly test their degree of stress and the restrictions imposed on their personal lives. We need easily identified targets that can be applied to as representative a proportion of the client group as possible, and we need to test the combined effects of all the principal contributors to the service. Defining outcomes for specific diseases or the effects of specific interventions is easier. The advantage of setting broadly based targets, however, is that careful attention will need to be paid to all the factors influencing the outcome of individual cases to be certain of reaching the target for the population as a whole. In this way the very process of measuring the outcome and planning how to meet the target will ensure that a reasonably comprehensive assessment is carried out and that hard thinking about the issues occurs in health districts.
This is a new and welcome approach to planning. As many of the outcomes are not currently measured with any accuracy, targets will need to be set in terms of percentage improvements on present performance. Current performance will therefore have to be measured to establish whether targets have been met. This information will subsequently allow absolute targets to be set.

I therefore suggest percentage reduction targets to be reached by 1996. By then absolute values would be known for all health districts so that during the following four years absolute targets could be set nationally.

To provoke discussion I have selected eight straightforward targets and seven that are more controversial. As rehabilitation medicine is concerned specifically with people aged 16 to 65 years, I have assumed that rehabilitation targets for children, elderly people, and people with psychiatric disability and mental handicap will be identified by the other authors in this series.

NON-CONTROVERSIAL TARGETS

- The annual incidence of pressure sores occurring in hospitals and residential institutions within each health district should fall to $50 \%$ of current values

- The prevalence of pressure sores in all health districts should fall to $50 \%$ of current values

- The incidence of limb fractures occurring as a result of falls due to impairment of mobility should decline to $75 \%$ of current values

- The prevalence of daytime incontinence from all causes that is sufficiently severe to necessitate a change of clothing more often than three times a month should fall to $75 \%$ of current values

- The numbers of people who because of difficulty in articulation or phonation are unable to communicate effectively other than with their relatives should fall to $75 \%$ of current values. People who communicate satisfactorily by using a communication aid are excluded

- The incidence of significant contractures (restricting the range of movement at the elbow, knee, or ankle joints by $20^{\circ}$ or more) developing during treatment for any cause in hospital should fall to $60 \%$ of current values in terms of both the number of limbs and the number of patients affected

- After traumatic brain injury the incidence of disturbances of behaviour requiring sedatives or major tranquillising drugs for more than 48 hours within six months after the injury should fall to $60 \%$ of current values

- The prevalence of carers of appreciably dependent people for whom sleep is interrupted on two or more occasions a night on three or more nights a week in order to help or supervise the disabled person should decline to $70 \%$ of current values.

\section{CONTROVERSIAL TARGETS}

- The prevalence of obligative wheelchair users who because of their physical impairment are unable without the help of another person to leave and enter their home and to travel up to $1000 \mathrm{~m}$ outside their home should decline to $75 \%$ of current values

- The prevalence of people with appreciable visual impairment who because of their disability are unable without the help of another person to leave and enter their home and to travel up to $1000 \mathrm{~m}$ outside their home should decline to $75 \%$ of current values

- The rate of employment for people with disabilities, registered and unregistered, whose form UB1671 indicates that they have a disability or health problem that restricts the nature or amount of work they can do 


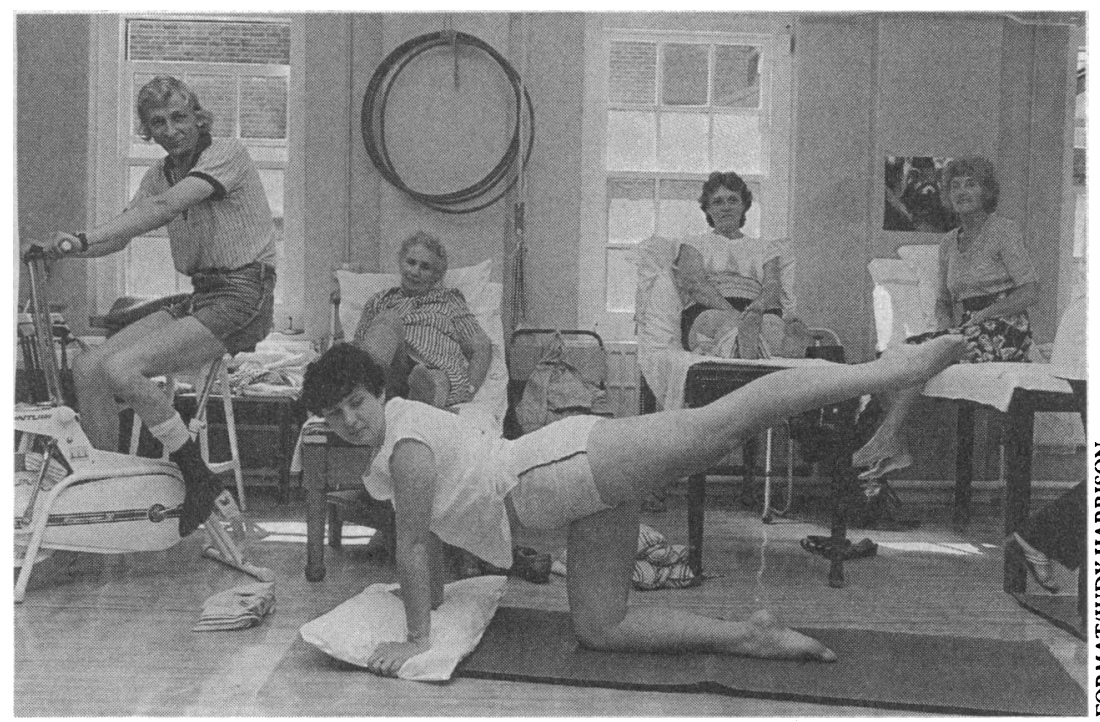

Though rehabilitation for people with acute disabilities is good, services for those with chronic illness or disability are scarce

should fall from $2 \cdot 8 \times$ the rate for non-disabled people to $2.0 \times$ the rate for non-disabled people in all employment department regions

- The incidence of clinical depression occurring during the first year of recovery from stroke or spinal cord injury should decline to $75 \%$ of current values

- The number of people who because of their physical disability are unable unless physically assisted by another person to visit their dentist or their general practitioner in his or her surgery should fall to zero

- The prevalence of clinical anxiety or depression in the main informal carers of appreciably dependent people should fall to $75 \%$ of current values

- The prevalence of clinical anxiety or depression in the main informal carers of people who have had a severe or very severe head injury within the previous five years should fall to $75 \%$ of current values.

What should be the strategy for reaching the targets?

To achieve these targets a rehabilitation task force should be set up in each district with an experienced manager supported by a small group that includes representatives of disabled people and senior professional staff from health, social, and local authority services. Hospitals would be required to identify people and audit the objectives in the following categories:

- People who habitually use crutches, walking frames, or wheelchairs for mobility who have been admitted with a stroke, head injury, pressure sores, spinal cord injury, and limb fractures

- Patients who develop the sentinel events of pressure sores or contractures in hospital

- People recovering from severe or very severe head injury who either develop contractures or require psychotropic drugs. (Though essential for management in some cases, drugs are frequently an ineffective substitute for more humane methods of behavioural management.)

Community services would be required to identify and monitor annually six groups of people:

- Those needing to use a wheelchair for all journeys outside their home

- Those recovering from a moderate or severe head injury within the previous five years

- Those who are appreciably dependent

- Those with severe impairment of vision

- Those with dysarthria severe enough to prevent communication except with family members
- The main informal carers of appreciably dependent people.

This would ensure the effective monitoring and selected audit of the objectives for some of the most vulnerable categories of people with disabilities, in cluding most of those who have been the subject of recent public concern-namely, disabled school leavers, people with multiple disabilities including the effects of head injury, and carers. The very process of monitoring and feedback is likely to improve outcome. ${ }^{13}$ I have no space to detail the precise interventions (most of which are self evident) that could help meet these targets. Success on the initial targets could be achieved by improvement in only some components of the service, but full success on the subsequent targets would require effective collaboration and combined action between rehabilitation medicine services in hospital and the community services, social services, housing, transport, and employment departments in each district. By 1996 enough information should be available to enable absolute targets to be set for each component of the overall rehabilitation service (allowing comparison between different districts) for the period from 1996 to the year 2000 .

What will be the problems in achieving these targets?

One problem in achieving these targets is that the targets themselves will be seen as arbitrary and excluding a lot of people with urgent needs. The present period of discussion is to help us define priorities. Once the targets are agreed our main problems will be obtaining informed commitment from NHS management and in funding the task groups needed to monitor and implement them. In most districts the skill needed is already available but is either too thinly spread or working too much in isolation to be effective.

In addition these targets are not scientifically or conceptually complex. They call for shrewdness and imagination on the part of directors of community health medicine, precision in the operation of rehabilitation sevices, and the ability of all concerned to work across professional and service boundaries in the interests of disabled people. Sniping between professions and, of course, lack of unity between the medical profession and disabled people about the importance of the final list of objectives are pitfalls we should be able to avoid. Can we really afford not to succeed?

1 Secretary of State for Health. The health of the nation. London: HMSO, 1991. (Cm 1523.)

2 Edwards FC, Warren MD. Health services for adults with physical disabilities. A survey of district health authorities, 1988/89. London: Royal College of Physicians, 1990.

3 Robine JM, Ritchie K. Healthy life expectancy: evaluation of global indicator of change in population health. BMJ 1991;302:457-60.

4 Office of Population Censuses and Surveys. Survey of disability in Great Britain. Vols 1-6. London: HMSO, 1988, 1989.

5 Cantrell EG, Dawson J, Glastonbury G. Prisoners of handicap. London: RADAR, 1985.

6 McLellan DL. Epilepsy and employment. f Soc Occup Med 1987;37:94-9.

7 Alexander JL, Willens EP, Halstead LS, Spencer WA. The relationship of functional assessment to evaluation of the quality of outcome in the rehabilitation process. In: Alperovitch A, de Dombal ST, Gremy S, eds. Evaluation of efficacy of medical action. Amsterdam: North Holland Publishing, 1979:287-307.

8 Thomas AP, Bax M, Smyth DP. The health and social needs of young adult with physical disabilities. London: MacKeith Press, 1989. (Clinics in Developmental Medicine No 106.)

9 Wilson BA. Future directions in the rehabilitation of brain injured people. In: Christensen A-L, Uzzell BP, eds. Neuropsychological rehabilitation. Amsterdam: Kluwer, 1988:69-86.

10 Godfrey HPD, Knight RG. Memory training and behavioural rehabilitation of a severely head-injured adult. Arch Phys Med Rehabil 1988;69:458-60.

11 Beardshaw V. Last on the list. Community services for people with physical disabilities. London: King's Fund, 1988.

2 Cornes $\mathrm{P}$. Roy $\mathrm{CW}$. Vocational rehabilitation index assessment of rehabilitation medicine service patients. Int Disabil Stud 1991;13:5-9.

13 Carpenter GI, Demopoulos GR. Screening the elderly in the community: controlled trial of dependency surveillance using a questionnaire administered by volunteers. BMF 1990;300:1253-6. 